\title{
El valor de la información no está en la información misma sino en su utilización
}

María Teresa Ramírez Vargas*

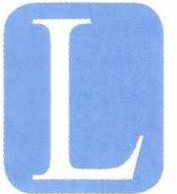

a sociedad de la información impone cambios culturales y organizacionales que obligan a modificaciones fuertes en la transmisión del conocimiento. Circulan múltiples discursos, producto de las nuevas formas de mediación tecnológica, que han hecho visibles lenguajes que el texto escrito había obviado, particularmente los lenguajes no verbales (íconos, gestuales y otros). De la misma manera que en su momento la escritura, y siglos mas tarde la tecnología de la imprenta, supuso una revolución que cambió la forma de acceder al conocimiento, las relaciones sociales y concepciones del mundo, hoy las nuevas tecnologías de la información transforman el panorama sociocultural y lo más oportuno en este momento, es repensar los diversos leguajes a la luz de las nuevas tecnologías y de las implicaciones sociales que suponen.

En la sociedad del conocimiento se abren nuevos ejes de debate en torno a la educación. Las exigencias se han hecho más dinámicas y variadas, porque educar para la sociedad de la información y el conocimiento “ es mucho más que cambiar libros por pantallas o monitores" además, requiere entre otros aspectos, conjugar lo mejor de la tradición crítica y la experiencia pedagógica con las nuevas opciones tecnológicas, cruzar los alfabetos escritos con las sensibilidades emergentes del nuevo entorno mediático. Las nuevas formas de transmitir información redefinen radicalmente la comunicación y el acceso a la información y el modo de producir conocimiento. Cambia la percepción de la gente con

* Directora de la Biblioteca Arturo Aparicio Jaramillo, Fundación Universitaria de Ciencias de la Salud Hospital de San José. Editorialista invitada. respecto a qué, cuándo, donde, y para qué conocer y aprender, cambia no solo es sistema de comunicación académica sino la forma en que operan las bibliotecas universitarias. ${ }^{1}$

\section{¿Y que cambios han experimentado las bibliotecas ante estos nuevos retos?}

Las bibliotecas se han redimensionado, han abierto sus fronteras hacia un desempeño más dinámico y diverso, que va mas allá de la interpretación de los datos, la disposición del material bibliográfico, las colecciones, los edificios. Tienen un claro objetivo, asistir a los usuarios en el proceso de transformar la información en conocimiento.

En la biblioteca de hoy, debe primar la calidad de los títulos, sobre la cantidad. El ritmo del cambio tecnológico ha convertido en obsoleto cualquier concepto de aislamiento o autosuficiencia, la biblioteca se mueve ahora dentro de un complejo mundo de información, que ni siquiera está presente en el campus universitario. Tampoco ha olvidado su papel tradicional de recoger y preservar la memoria de los pueblos pues, "somos y seremos lo que hemos sido y lo que hemos reflexionado y progresado a partir de lo que hemos sido, individual y colectivamente". ${ }^{2}$

Como el valor de la información no está en la información misma sino en su utilización, hay un gran interés por capacitar a los usuarios en el manejo y uso de la información, pues a lo que se aspira es contar con usuarios autónomos y llevarles la información a sus sitios de trabajo. 
Por otra parte, los recursos de las bibliotecas se multiplican enormemente y se racionaliza su uso, porque existe interés por participar en las redes académicas y el trabajo interinstitucional.

La tecnológica ha invadido por completo las rutinas y los espacios de la biblioteca, y los recursos audiovisuales tradicionales han evolucionado hacia productos en multimedia e hipermedia.

Por último, independientemente de la forma en que la biblioteca esté dentro de la estructura de gobierno de la universidad, debe haber un flujo adecuado de información hacia la biblioteca con relación a los cambios fundamentales que se puedan producir en la misión de la universidad y en sus programas.

Lo anterior indica que las bibliotecas universitarias deben convertirse en expertas en el proceso de examinar y redefinir su propia misión, establecer metas coherentes para medir y sopesar continuamente sus logros con el fin de determinar su eficacia para resolver los problemas de los usuarios, e identificar y aplicar aquellas medidas que sirvan para descubrir hasta dónde se ha tenido éxito a la hora de cumplir con su misión. ${ }^{3}$
Desafortunadamente en nuestro país el acceso al maravilloso mundo de la información es casi una utopía. Si bien es cierto que la situación ha mejorado, las estadísticas son poco halagüeñas, pues en el año 2001 Soto C. F. indicaba que en Colombia los usuarios de Internet apenas alcanzaban a 1.154.000, lo que representaba el $2,7 \%$ de la población, el porcentaje más bajo comparado con Argentina, Brasil, Chile, Méjico, Perú, Uruguay y Venezuela. El desafío está en capacitar en forma masiva a los jóvenes en el uso productivo de las tecnologías de información y comunicación. Se requiere una gran inversión para reducir esta brecha que agudiza los contrastes entre regiones, países y grupos sociales.

\section{Referencias}

1,4 CEPAL. La juventud en Iberoamérica: tendencias y urgencias. Santiago de Chile: CEPAL, 2004. P.196, 198,258. Disponible en www.eclac.cl

2. Sosa-Iudicissa M. La información: piedra angular de las ciencias médicas. En: Internet, telemática y salud. Bogotá: Médica Panamericana, 1997. p.53.

3. Saldarriaga, J A. Estándares de calidad para bibliotecas universitarias colombianas. Bogotá: 2002.

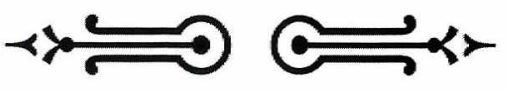

